\title{
Consecuencias de la Nueva Ruralidad en Chile Central: identidades mixturadas y representaciones sociales en comunas rurales de la VI Región y Región Metropolitana. SERGIO GONZÁLEZ R. \\ > Universidad de Santiago de Chile, Santiago, Chile. sergio.gonzalez.r@usach.cl \\ AMAYA PAVEZ LIZARRAGA \\ > Universidad de Santiago de Chile, Santiago, Chile. amaya.pavez@usach.cl
}

Universidad de Valparaíso

Facultad de Arquitectura

Revista Márgenes

Espacio Arte Sociedad

Consecuencias de la Nueva Ruralidad en Chile Central:

identidades mixturadas y representaciones sociales en comunas

rurales de la VI Región y Región Metropolitana.

Septiembre 2016 Vol. 13 № 18

Páginas 33 a 40

ISSN elec. 0719-4463

ISSN imp. 0718-4034

Recepción: septiembre 2015

Aceptación: noviembre 2015

\section{RESUMEN}

Los determinantes cambios ocurridos en el mundo rural de Chile en los últimos cincuenta años -con el inicio de los procesos de reforma agraria- han significado no solo transformaciones estructurales en los ámbitos productivo-económico y sociocultural en una acelerada y paradojal modernización. Junto a ello se observan, nuevas formas y construcciones identitarias -individuales y colectivas-, que se han constituido como consecuencias de los convulsos escenarios de la nueva ruralidad que ha transformado el paisaje físico y cultural de Chile Central. Se refieren los impactos indagados a nivel de las representaciones sociales como formas de autopercepción, al igual que los cambios en los proyectos y estilos de vida como contenidos intersubjetivos de las nuevas identidades mixturadas. Se enfatizan las dimensiones de las relaciones intergeneracionales y de género como las expresiones más acentuadas de estos impactos en las comunas rurales de la VI Región y Región Metropolitana de Chile Central ${ }^{1}$.

PALABRAS CLAVES

nueva ruralidad, identidades mixturadas, representaciones sociales, Chile Central

\section{Consequences of the New Rurality in Central Chile: Mixed identities and social representations in rural communes of the VI Region and the Metropolitan Region. \\ ABSTRACT}

The determinants changes occurring in the rural world in Chile in the last fifty years, with the processes of agrarian reform, have meaning not only structural transformations in the productive-economic and socio-cultural areas product of an accelerated and paradoxical modernization. Next to this are observed, new forms and constructions of identity -individual and collective- that have been constituted as consequences of the convulsive scenarios on the new rurality that has transformed the physical landscape and cultural of Central Chile. Relate the impacts investigated at the level of the social representations as forms of self-perception, as well as changes in the projects and styles of life as contents of the intersubjective of the new mixturadas identities. It emphasize the dimensions of intergenerational relations and gender as the sharpest expressions of these impacts on the rural communes of the VI Region and the Metropolitan Region of Central Chile. KEYWORDS

new rurality, mixed identities, social representations, Central Chile 


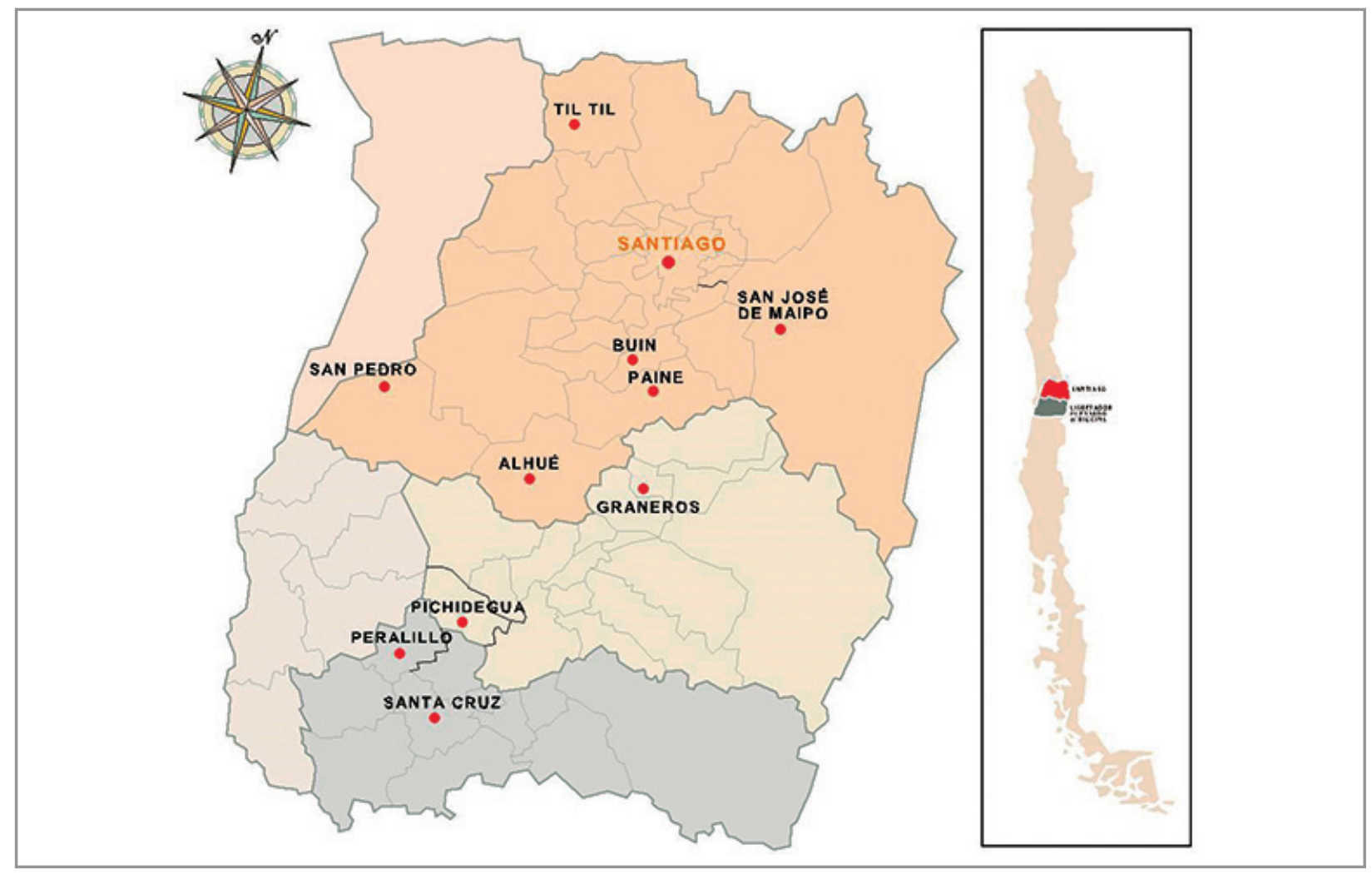

Figura 1. Comunas rurales de la VI Región y Región Metropolitana de Chile Central incluidas en el estudio.

\section{INTRODUCCIÓN}

El medio rural de Chile Central ha recibido procesos de transformación profundos en los últimos 50 años que han significado la implantación de modelos modernizadores con más paradojas que coherencia. Modelos que han sido contrapuestos y han competido entre sí y, no obstante, han representado indirectamente continuidades y discontinuidades desde la implantación de los procesos de reforma agraria que se llevaron en el país. La realidad rural y su ordenamiento experimentaron cambios profundos que comienzan con los procesos de reforma agraria llevados adelante en las décadas de 1960 y 1970 por los gobiernos de los presidentes Frei Montalva y posteriormente de manera más radical, por Salvador Allende. No se puede hablar y comprender los procesos modernizadores del medio rural y del agro nacional sin estos procesos de transformaciones profundas que posteriormente, a pesar del signo contrapuesto que tuvo el proceso de Contrarreforma en el campo, llevado adelante por la dictadura, que permitió paradojalmente y con otro signo, la modernización y liberalización de las relaciones de un medio rural que no había experimentado transformaciones significativas por 450 años desde la dominación colonial y semifeudal que representa el sistema de la encomienda y su continuidad en el modelo de la hacienda que perduraron desde la llegada de los españoles al territorio nacional hasta estos procesos transformadores de reforma agraria.

Por tanto, las transformaciones de la ruralidad en chile comienzan a ocurrir de manera relevante y profunda desde la década de los años sesenta del siglo pasado ${ }^{2}$. Así junto a la emergencia de nuevas estructuras, institucionalidades y dinámicas sociales, políticas y económicas se han conjugado cambios que en lo cultural han significado nuevas formas, procesos y estilos de vida que los habitantes del medio rural han debido asimilar, resistir, traducir, co-construir y reproducir en su interacción constante con las con- vergencias modernizantes de la sociedad mayor y neoliberal. Estas situaciones han generado diversas complejidades, paradojas que de manera directa llamaremos disrupciones y transiciones en que el medio rural ha estado reconstruyendo sus procesos identitarios individuales y colectivos, y los estilos y proyectos de vida de las personas que habitan las ruralidades del país. El impacto en las subjetividades de los habitantes del medio rural es significativo y sus consecuencias están en correspondencia con las derivaciones que producen los fuertes procesos de cambio social y cultural en los procesos de modernización radical inducidos por el medio externo (Giddens, 1999; Beck et al, 1997).

Hemos entendido que uno de los impactos más destacados dice relación con la continuidad temporo-espacial que se ha producido entre lo que anteriormente se inscribía en la dicotomía de diferenciación urbano-rural. En la actualidad estos conceptos refieren un continuo cuyos límites no son fácilmente delimitables. De este modo, la sociedad de la información ha tendido a leer el campo como una prolongación de los modelos dominantes que dicta la globalización tanto en sus aspectos positivos como negativos. Entre los primeros, encontramos la amplitud y la cobertura de acceso a servicios básicos, mayores niveles de escolarización, nuevos planes de igualdad de oportunidades, término del aislamiento y del funcionamiento cerrado de las comunidades, entre otros. Entre los aspectos negativos, se destaca a nivel cultural la pérdida de elementos simbólico-identitarios, a nivel productivo la explotación extensiva e intensiva de los recursos naturales -tal vez como nunca se había efectuado antes-, la entrada de manera compulsiva de pautas de consumo uniformes, la segmentación y diferenciación social marcada con la contradicción evidente que provoca el acceso masivo a la información. Todos estos aspectos, que son una parcialidad, dentro de una gama de nuevas condiciones en que el 
mundo rural se reproduce permiten hablar, de manera cierta, que asistimos a un proceso diacrónico de lo que se puede llamar una nueva ruralidad (González, 2006, 2010). Esta nueva realidad de los territorios rurales es abierta, paradojal y diversa reproduciendo todas las asimetrías del sistema neoliberal dominante, al mismo tiempo que permite la integración y participación en el stock de bienes, servicios y conectividad en lo instrumental y, de manera más lenta en la construcción de derechos y ampliación de autonomía de los actuantes que implica la modernidad. Estos procesos que tienen su desarrollo discontinuo y paradojal determinan los escenarios de las nuevas ruralidades que en nuestra lectura han tenido en el país el mayor impacto en las zonas de Chile central donde desde una perspectiva histórica la matriz cultural fue determinante para la identidad colectiva del país.

En este contexto toma relevancia el problema acerca de la nue va ruralidad del Chile Central. En el presente escrito relevamos la sistematización del trabajo de campo y el análisis de lo indagado específicamente en comunas de alta ruralidad en la VI Región y en la Región Metropolitana (Berdegué et al, 2010). Un aspecto que hemos abordado en forma especial, dice relación con los impactos de estos procesos de transformación en la intersubjetividad colectiva y en la subjetividad de los habitantes rurales de las regiones de Chile Central. De este modo, consideramos que se debe responder la pregunta sobre los impactos de la modernización en la identidad individual y colectiva de los habitantes del sector rural de estas Regiones. De allí que indagar en las re-significaciones y representaciones colectivas de los efectos de estos cambios es una tarea necesaria para comprender desde una perspectiva emic las transformaciones en curso.

\section{IDENTIDADES Y SUBJETIVIDAD}

La identidad es una de las principales fuentes de significado y experiencia para las personas. La podemos entender como el proceso de construcción del sentido atendiendo a un atributo cultural, o un conjunto relacionado de atributos culturales, al que se da prioridad sobre el resto de las fuentes de sentido (Castells, 1998:28). Para un individuo determinado o un actor colectivo puede haber una pluralidad de identidades, la cual es una fuente de tensión y contradicción tanto en la representación de uno mismo como en la acción social. Este autor distingue la identidad de los roles. Los roles se definen por normas estructuradas por las instituciones $y$ organizaciones de la sociedad. Las identidades, por su parte, son fuentes de sentido para los propios actores y son construidas por ellos mismos mediante un proceso de individuación. O sea, las identidades organizan el sentido, mientras que los roles organizan las funciones. Además, la identidad del sujeto depende de las representaciones sociales (R. S.) $)^{3}$ que este genera de su propio yo, al mismo tiempo que las representaciones sociales que el sujeto tenga de sí mismo dependen de las condiciones socioeconómicas y de las diversas instancias fundamentales de su socialización primaria y secundaria. En esta última encontramos la influencia de la institución educativa, los medios de comunicación y la comunidad (Moscovici,1993; Jodelet,1984).

En lo referente al debate actual acerca de la "identidad latinoamericana", según Larraín (1994) encontramos dos posiciones teóricas: Una, de carácter "esencialista", plantea que existe una esencia latinoamericana en nuestro pasado histórico, la cual se encuentra congelada en el mundo indígena o bien en una fusión mestiza originada en el Barroco americano del siglo XVII. Por otro lado, existe una corriente de pensamiento que destaca el carácter problemático de la identidad, situándola como una constante búsqueda en la cual conviven las diferentes herencias culturales que hemos recibido y continuamos absorbiendo. En síntesis, según esta segunda posición, la identidad es un proyecto que se construye día a día sin esencias elementales, sino como una superposición de tradiciones, pensamientos e ideologías provenientes de distintas partes del mundo.

Sostenemos que para poder comprender la identidad rural es necesario considerarla como una hibridez cultural (García Canclini, 1992) producto de un proceso de construcción recursivo y permanente que independientemente de los contenidos de los cuales se nutra, sólo puede ser entendida como un fenómeno focalizado regional y localmente en su expresividad conductual. En este sentido, la construcción de la identidad rural es un proceso circunscrito espacio-temporalmente a determinadas condiciones culturales, sociales y productivas. En Chile, estas condiciones han estado atravesando un significativo proceso de cambio en las últimas décadas. Sus repercusiones han impactado fuertemente en las dinámicas de la ruralidad, influyendo en nuevos desarrollos emic-etic de significación identitaria en su constante proceso de transformación. En este sentido, hipotetizamos una mayor intensidad de estas transformaciones en la VI Región y en la Región Metropolitana, en donde la disociación entre lo urbano-rural es más difícil, principalmente porque la interacción entre el mundo rural y urbano se da en un espacio regional en el cual la diversidad de ofertas ideográficas, de agentes, de servicios y equipamientos es significativa al compararla con el resto del país. Consecuentemente, las nuevas realidades configuran el entender la noción de identidad rural en una lógica de collage, de superposición de contenidos cognoscitivos que se complementan y/o se colisionan con los esquemas ya existentes y que, por lo general, no alcanzan a constituirse sólidamente en su asimilación por parte de los habitantes rurales cuando son interpelados por nuevos contenidos homogenizadores y altamente valorados por la cultura dominante (González, 2010). La reflexión actual sobre la mixturación de contenidos culturales indica un panorama de alta exposición y complejidad.

Hasta la licuación del entorno social y del modo de vida moderna, la cultura operó como un conjunto de normas vinculantes; ahora es una compilación de ofertas y tentaciones. También ha sido desistematizada: vivimos en un entorno multicultural, lo que significa estar expuesto a un conjunto desordenado de dispersiones, de estímulos y entusiasmos descoordinados y muy a menudo contradictorios, incluso incompatibles, que compiten por ser elegidos por la fuerza de su atractivo, no por su influencia o peso (no por el juicio ligado a las elecciones). La cultura está sometida a los procesos interconectados de mercantilización de las ofertas culturales y de la privatización de sus elecciones (Bauman, 2015).

Más allá de la mirada pesimista de este autor, queda en evidencia la trama de paradojas e imperativos en la radicalización de los procesos de hibridación cultural a los que asistimos en los diversos espacios culturales, a los que no escapa, por cierto, el espacio rural, más allá de nuestras convicciones y sensibilidades.

Revista Márgenes № 18 Vol $13>$ Septiembre $2016>35$ Facultad de Arquitectura > Universidad de Valparaíso 


\section{MODERNIZACIÓN Y RURALIDAD}

Las transformaciones de la modernización del medio rural se han realizado en un proceso digitalizado desde el medio externo, es decir, desde el mundo urbano que vehiculiza el acceso a los contenidos globalizadores. El medio rural ha sido más bien determinado y conminado a una modernización que en sus tiempos están lejanos de las características propias del mundo rural. Tal vez, esta situación se corresponde con los impactos negativos en que la modernización sin dejar de ser aceptada en el medio rural no ha tenido las condiciones de adaptación para que los procesos se realicen de manera asimilable para este mundo que ha vivido los cambios como consecuencias que debe aprender sobre la marcha a manejar e incorporar, por una parte, y a resistir y re-significar por otra. Esto no es lineal y se expresa de igual manera en los diversos agentes del mundo rural, existiendo marcadas diferencias generacionales y de género, entre otras.

Entre las modernizaciones del mundo rural son destacables el dinamismo alcanzado de los procesos productivos y las nuevas tramas de relaciones capitalistas que se consolidan entre los actores productivos con sus nuevas formas de convivencia social que han generado. Son destacables en la representación social de la modernización del mundo rural, justamente, dos aspectos característicos. Por una parte, el impacto de la entrada y masificación del acceso a las tecnologías que no sólo han revolucionado los procesos productivos, sino que los "estilos de vida" de los colectivos e individuos del mundo rural. En segundo lugar, se destaca la iconización de la modernización en los bienes tecnológicos específicos que son asumidos como necesarios y deseables para el mundo rural del presente y el futuro.

En relación a los dos aspectos anteriormente señalados es destacable la relación entre los elementos tecnológicos (maquinarias, telecomunicaciones, carreteras, medios de transporte, entre otros) con el nuevo papel o rol integrador que su acceso representa para las personas del mundo rural. De este modo, el acceso a la tecnología significa compartir de manera equivalente al mundo urbano, un "pool de artefactos" y de condiciones de vida en que destaca la centralidad de los estándares homogéneos de una cultura dominante, que también forma parte del "imaginario" de los actores sociales del mundo rural. No obstante existen cierres positivos de la modernización, objetivada en las tipificaciones de las representaciones sociales, nos permiten hablar de una asociación directa entre modernización y calidad de vida, la cual es una condición irrenunciable en las aspiraciones del mundo rural representado, sin que ello signifique contradicción con la consiguiente pérdida de diferenciación con importantes realidades y significados urbanos (González, 2006). Se constituye en líneas generales un perfil aspiracional en que se mixtura lo urbano y lo rural. Se aspira a contar con los medios y condiciones de la realidad urbana sin abandonar los contenidos de lo característico de lo rural que es percibido como positivo, es decir, el medio ambiente natural (paisaje), las condiciones de calidad de vida, la relativa mayor seguridad ciudadana, entre otras condiciones evaluadas como positivas. La modernización no sólo es un medio sino que es un fin a alcanzar, con la salvedad que sus contenidos deben ser incorporados de acuerdo a una matriz establecida por los proyectos de vida actualmente en construcción, es decir, por condicionantes que aún son discursos fragmentarios de un deber ser que el mundo rural está elaborando y urdiendo con características propias y diferenciadoras.

\section{IDENTIDADES CONVULSAS}

La perspectiva asumida sobre el circular tema de la identidad puede ser entendida en la complejidad manifiesta que el medio externo significa para las personas y los colectivos. En este sentido Ricouer señala que en la noción de identidad hay solamente la idea de lo mismo, en tanto el reconocimiento es un concepto que integra directamente la alteridad, que permite una dialéctica de lo mismo y de lo otro. La reivindicación de la identidad tiene siempre algo de violento respecto del otro. Al contrario, la búsqueda del reconocimiento implica la reciprocidad (Ricouer, 1995:96).

El planteamiento de fondo que lleva a una reflexión de la noción comprende, de manera conjunta, al menos tres tipos de aspectos: 1 . Sobre los procesos de identificación, la que no solamente implica mera subjetividad, sino que también contiene elementos comunitarios, culturales y de interacción, con los cuales un individuo conforma identidades. 2. Sobre las modalidades de la pertenencia comunitaria (familiar, confesional, étnica, social, nacional, latinoamericana...) por las cuales se constituye un ser-en-común, una unidad comunitaria y una identidad colectiva. 3. Sobre las relaciones de subjetivación por las cuales un sujeto privado, identificado por sus pertenencias comunitarias, alcanza, llevado por la acción pública al seno de las confrontaciones políticas, la dignidad de actor político, es decir, de ciudadano. Estas tres interrogantes se entrecruzan de manera compleja cuando se trata de definir características propias de una comunidad política y no exclusivamente económica, social o cultural, y, por tanto, a los miembros que la constituyen los reconocemos como ciudadanos. Así pues, el eje de la discusión se desplaza a entender la cuestión política propiamente dicha, no en la dimensión de la identidad comunitaria, sino en la dimensión de la identidad pública. El encuentro de las particularidades identitarias debe ser resuelto en un espacio de protección y reconocimiento común en que se legitiman las diferencias en auténtica convivencia. Este espacio de convergencias sin amenazas debe estar abierto a la aceptación de ciertos niveles de ambigüedad en el plano cognoscitivo, en que la relatividad inevitable, que supone la confluencia de contenidos diversos, apunta a una matriz de multiculturalidad que debe actualizarse de acuerdo a las renovadas realidades socioculturales que se van presentando. Este espacio inequívocamente es el de la Ciudadanía. Como señala García Canclini: Cuando ese soporte legitimador de las identidades que es la ciudadanía no se reforma para abarcar la escala supranacional de las actuales relaciones sociales, no sabemos cómo llamar a los otros... Una cultura política y una política cultural democráticas son aquellas que no sólo admiten las diferencias, sino que crean condiciones para vivirlas en ambigüedad (García Canclini, 1999:125). La ambigüedad como superposición de contenidos en las identidades en un espacio con transiciones en marcha forma parte, hoy día, del paisaje psicosocial y antropológico de los territorios de las ruralidades.

A través de las R. S. los grupos, las subculturas y las sociedades se piensan a sí mismas, producen la reflexión colectiva con la cual en la modernidad se maneja la incertidumbre. De este modo, en estos procesos comunicativos y discursivos, mediante las R. S. se caracteriza y objetiva el estilo de pensamiento de los miembros de los grupos sociales. Desde la conversación entre amigos y conocidos hasta el impacto de los contenidos de los medios de comunicación de masas, se adquieren elementos nuevos, imágenes y metáforas que son buenas para pensar, que no son necesariamente verdaderas en el sentido estricto del término. Lo importante es que el 
pensamiento individual se convierte en una práctica social (Arendt, 1987). Así podemos hablar de pensamiento de grupo o de pensamiento social. De allí que en la teoría de las R. S. se enfatice una forma de comunicación y pensamiento cotidiano en el mundo actual (Moscovici, 1988). Esta forma de pensamiento colectivo que caracteriza la reflexividad de los grupos es condición fundamental para la recursividad de la identidad social. Es decir, la identidad social implica, por una parte, la identificación con los grupos a los cuales se pertenece, y, por otra, que es el grupo el que genera un acervo, una mirada común que contiene conocimientos, modelos de justificación, sentido común, que permite a sus miembros situarse bajo un espacio discursivo compartido. Así entendida, la identidad social permite a las personas dar verosimilitud a sus creencias, teniendo a su disposición evidencias legitimadas culturalmente. De este modo, las representaciones sociales tienen una verdad fiduciaria, que es generada por la confianza que depositamos en la información y los juicios cuando compartimos con otras personas (Moscovici, 1988:233).

Se ha utilizado la noción de representaciones sociales para condensar y sistematizar los múltiples y extensos significados generados en las 90 entrevistas en profundidad y 12 grupos de discusión que constituyeron el trabajo de campo junto a la etnografía y observación activa de los estudios reportados.

\section{DISCUSIÓN Y LÍNEAS DE CONCLUSIONES}

A continuación se presentan líneas de conclusiones centrales de los estudios realizados en las comunas rurales incluidas en ambas regiones de Chile Central. Se han distinguido unidades temáticas para facilitar su discusión y posible utilización en las aplicabilidades que de ellas se desprenden.

\section{Identidad rural compleja}

Se observa, pese a la heterogeneidad de identidades que conforman las nuevas realidades de la Ruralidad en que el impacto de las modernizaciones y que las exigencias actuales han significado cambios significativos en diversos niveles.

Las continuidades y discontinuidades que se expresan hoy en los territorios rurales reafirma la convicción sobre la necesidad de superar la dicotomía mecánica urbano/rural y dar cuenta de la mixtura de espacios y conformaciones en que se manifiesta más bien una gradiente entre estos dos ámbitos que nos debiera permitir hablar de ruralidad variable (Berdegué, J. et al, 2010). De este modo, acercarse a comprender la superposición de los planos y contenidos de los mundos complejos en que se expresan los orígenes rurales y urbanos, tradicionales o modernos, locales o globales con contenidos que son resignificados por los actuantes en su capacidad individual y colectiva de reconvertir, asimilar, resistir, integrar, reconstruir en sucesivos procesos de co-construcción de los esquemas cognoscitivos en que se expresa la actual complejidad, que no pueden ser consignados como expresiones de asepsia cultural o de pureza esencialista. Así, la hibridez y la mixturación en la conformación de las representaciones sociales de la realidad son condiciones de respuesta y de negociación activa -incluso, en la subordinación existente en las relaciones económicas y sociales- de manera permanente entre los anclajes provenientes de la tradición, a la vez de la reelaboración de los contenidos exógenos a los que se está sometido. Por cierto, que estos complejos procesos no se expresan de manera homogénea y sin la presencia de los conflictos que implica la asimetría en la presencia o ausencia de capacidades y de repertorios cognoscitivos que las personas de los territorios rurales al igual en muchos casos que del medio urbano van a poder disponer en el ejercicio de su autonomía en el contacto con las diversas propuestas endógenas o exógenas circulantes en el mundo rural. Una expresión significativa de esta situación la encontramos en el ejercicio relativo de la capacidad de decisión en las opciones ofertadas para la conformación de los proyectos de vida y, a través de ellos de la asunción de los estilos de vida que son expresados por los modelos a los que las personas están expuestas (homogeneizados y globalizados) directa e indirectamente. De igual modo, es de gran relevancia constatar que en el caso de mujeres y jóvenes, a través de la integración al trabajo remunerado y a los desplazamientos territoriales, han significado la ampliación de los derroteros para aplicar estos principios de opcionalidad en los proyectos y estilos de vida constituyendo una matriz de cambio social y cultural.

A partir de la diversificación de las actividades productivas por parte de la población, las cuales se realizan estacionalmente y en estrategias múltiples, han implicado el relacionamiento con diferentes actores complementarios. Incluso a nivel de pequeñas producciones, la presencia de numerosos programas sociales, asistenciales y de servicios por parte de los municipios y agentes externos privados y estatales amplían los círculos de relaciones de reciprocidad y conflicto en los espacios propios de las comunidades. La necesidad percibida por parte de la autoridad local, de capacitar tanto en temas relativos a la asistencia técnica para la producción, como también a la distribución y comercialización de los productos, independientemente de los efectos económicos concretos de estos programas y tácticas laborales difuminan y abren las interacciones a nuevas fuentes comunicadoras y a nuevas relaciones con actuantes diversos y mutuamente dependientes. La representación social de estos agentes es significativa porque los integra en un habitus rural diverso en que se horizontaliza la percepción de lo foráneo al entenderse, por ejemplo, en los ámbitos de los servicios de educación, salud y de la asistencia técnica como parte de una nueva matriz de relacionamientos que finalmente expresa, "una incipiente cultura de derechos" en que los agentes del estado son demandados de manera creciente y directa sin mayores resabios de servilismo o clientelismo. Una situación que implica un cambio de percepción muy profundo.

\section{Identidades fragmentadas determinadas desde la alteridad}

Lo rural como un estilo de vida que sin renunciar a su singularidad no quiere quedar fuera de la integración en una totalidad social (todo social) que se encuentra digitalizado por lo urbano, por los contenidos dominantes. La integración en los espacios, programas y políticas públicas homogeneizadoras que se consideran parte de una necesaria visión niveladora e igualitarista, en la cual no se debe quedar marginado, contando con elementos de corrección (acción positiva) para alcanzar a calificar en dichas oportunidades, junto a propuestas y ofertas propias de los espacios rurales. La tendencia a la integración es una forma de validación del propio modo de vida en el medio nacional dominante, significada en los valores del modelo neoliberal y en la acción privada, cuya acción rectora está representada en el Estado.

En la conformación de la identidad rural, también, asistimos al proceso de devolución de una imagen reflejada desde la alteridad (desde lo urbano) que está constituida por lo esperado y por las expectativas que se tiene desde el espacio urbano y de los determinantes globalizantes. Lo que es contenido de deseo para los vi- 
sitantes, pasajeros o rondadores urbanos por los circuitos de la nueva ruralidad. En este sentido se conforma la ruralidad como expresión de deseo, como aspiración frente a lo que no se tiene y como una forma de realizar zapping social en un espacio al que no se pertenece pero que en contenidos específicos se valora y se de sea. Esto no es refractario para el medio rural, muy por el contrario, es percibido y valorado para ser integrado como parte de la oferta que el espacio rural hace a su contraparte, por lo cual se integra sin mayores dificultades a contenidos que conforman su identidad. Son cada vez más numerosos e importantes las ofertas en diversas escalas de los emprendimientos de turismo rural.

Una perspectiva actual del tratamiento de las identidades las concibe como un curso diacrónico en sus continuidades y discontinuidades integrando los contenidos de pasado (memoria), presente (reconocimiento) y futuro (proyecto) (Castell, 1998). Esto implica asumir en programas e iniciativas la necesidad de integrar los elementos de memoria, de historia común, junto a las opciones presentes y a las proyecciones de lo que se quiere o desea ser. Estas articulaciones complejas de contenidos plurales implican, también, fracturas culturales en que se debe intentar conjugar elementos diversos no armónicos entre sí, que reflejan valores, actitudes, motivos, aspiraciones en que las pertenencias locales y las referencias culturales globales se superponen y colisionan expresando el encuentro y desencuentro entre los contenidos de los proyectos de vida personales y la gramática social circundante en un sentido amplio (González, 2008).

Por otra parte, las comunas estudiadas no convergen en una sola identidad cultural, encontrando al interior de las comunas diferentes gradientes de ruralidad, al igual que en el resto del país, la ruralidad actual es heterogénea (Berdegué, J. et al, 2010; PNUD, 2008). De manera ilustrativa, en la comuna de Pichidegua las nueve localidades en las que está dividido el territorio tienen una línea identitaria propia y se distinguen del resto en la gradiente urbana-rural. La localidad de Pichidegua estaría situada en el extremo urbano de la gradiente siendo la que alberga al gobierno local y servicios. Esta zona es el centro urbano de referencia para el resto de las localidades, las personas hablan de ir a Pichidegua de este modo se despliega un nuevo nivel en la gradiente urbanorural al interior de la misma unidad, esto difiere a las referencias del indicador oficial TV (tiempo de viaje desde centro poblado comunal más importante a polo urbano más cercano) y muestra la heterogeneidad de la comuna.

Por otra parte, es relevante la continuidad de la autopercepción, a pesar de las transformaciones, así, las personas refieren la ascendencia que en ellas tiene la presencia del sistema social y productivo que representó anteriormente el fundo (pasado) y que se proyecta a la empresa (presente) situados en su territorio en tiempos trastocados. Se observa que cuando los habitantes tienen una relación con familias tradicionales anterior a la reforma agraria y/o cuando son empresas exitosas económicamente, las personas perciben seguridad y protección junto con mejores condiciones de trabajo por ser instancias que asimilan mano de obra y refieren la práctica de apadrinamiento a la localidad asociándose simbólicamente al éxito y prestigio de la empresa. Lo contrario sucede en aquellas localidades en que las nuevas empresas agropecuarias son pequeñas, con menor presencia corporativa o que son emprendimientos de parceleros que trabajan solos. Ambos son vistos con bajo prestigio social y se asocian con localidades de menor desarrollo y con una devaluación identitaria. Por tanto, al interior de la comuna pervive diacrónicamente la asimetría social y se reproduce una continuidad en la hegemonía sobre la ruralidad campesina tradicional. Así, los modelos de prosperidad y calidad de vida son atribuidas en el presente a la dominancia que está representada por la empresa-industria en el sistema neoliberal actual. Como se ha indicado: Con la pérdida de referencia de forma que una totalidad imaginaria lo que la gente fue capaz de creer que pertenecía y en las que creían que podrían buscar (y tener esperanza de encontrar) refugio, se abre un vacío en el lugar que en otro momento fue ocupado [en este caso por la relación hegemónica] (Bauman, 2008). Este vacío moderno se completa con los significados tradicionales. De este modo, en localidades donde se generan verdaderos bolsones de marginalidad determinadas por situaciones de pobreza asociadas a la ruralidad tradicional, a baja empleabilidad por la falta de oportunidades, por la pérdida del referente dominante y quiebre de la complementariedad en la relación de clase, se observa, comparativamente con las otras localidades adyacentes, baja autoestima, violencia de género, embarazo adolescente, alcoholismo y consumo de drogas. De manera determinante se constata una mayor asimetría social en estos espacios devaluados de las comunas, todo lo cual influye en la baja autopercepción y la exclusión simbólica, en tanto las otras localidades comunales refuerzan su prestigio y autopercepción al confrontar su autoimagen con esas localidades devaluadas.

En esta identidad fragmentada se observa un desarrollo desigual en una relación entre desarrollo y cultura de las localidades, asociándose un menor desarrollo a la pervivencia de la cultura tradicional campesina y al menor prestigio de la localidad. Las localidades con mayor prestigio se asocian a una cultura de transición y/o de modernidad en curso. El riesgo social aumenta en las localidades devaluadas y marcadas con un estigma social, su aumentada vulnerabilidad es factor riesgo que puede potenciarse con situaciones generadas en el proceso globalizador, como la influencia de agentes exógenos dañinos a la comunidad, estilos de vida urbanos generados por las características laborales que ofrecen las empresas agrícolas que se rigen por el derecho de la empresa privada siendo indistinto el trabajar en una empresa en Santiago, Pichidegua o en Paine porque el régimen laboral, las rutinas, está sujeto a la misma lógica. Esta situación de choque cultural modela comportamientos y proyectos de vida disruptivos y disfuncionales para las personas que pueden favorecer la formación de guetos (Bauman, 2008) al interior de las mismas comunas donde se reproduce la desigualdad y la pobreza, ahora entre las diversas localidades de una misma comuna rural. En este sentido es interesante constatar que a pesar que comportamientos e identidades que eran reprimidas o estigmatizadas como las formas de homosexualidad en estas nuevas realidades rurales se permiten espacios de expresión manifiesta y de reconocimiento de estos desarrollos identitarios, pero de igual modo, se reproducen los márgenes al conformarse espacios de expresión físico y simbólico que se constituyen en nuevos guetos, sin superarse la lógica de la marginalidad, pero con un reconocimiento acotado que permite su visibilización y expresión social.

\section{Imágenes de las transiciones en las identidades de género}

La expresión del género es reflejo de la complejidad del proceso de transformación sociocultural, observar y analizar el sistema de sexo-género permite visibilizar los espacios de tensión cultural en las representaciones y comportamientos de hombres y mujeres. Los cambios producidos en la sociedad rural-urbana afectan al género porque inciden en la estructura y función social al cambiar 
el estatus y el rol de las personas. El género es una categoría de análisis que puede pasar inadvertida, su invisibilidad no implica su inmutabilidad y trascendencia, la relación entre el significado de ser hombre y ser mujer es consustancial a la organización social y por tanto es una de las dimensiones del ser humano de mayor sensibilidad a los cambios y modificaciones socioculturales.

Las diferencias en la identidad, en el desarrollo desigual, en el binomio cultura-modernidad, implican cambios en los estilos de vida, en la organización social tanto en el ámbito urbano como rural que conlleva una resignificación del sentido de vida, de los valores y creencias que modifica el sistema sexo-género, esta dinámica favorece la emergencia de nuevos modelos que en estas investigaciones se representan principalmente en la adscripción a las representaciones de la feminidad y masculinidad del modelo urbano-globalizado inmerso en la ideología neoliberal. Asistimos a continuidades y emergencias en la significación de la feminidad y de la masculinidad, en una mixtura con los modelos de la cultura tradicional y de la modernidad radical de forma que conviven la diferenciación de roles reproductivos para las mujeres y productivos para los hombres, con la inclusión laboral de las mujeres y las tareas de cuidado para los hombres. La inclusión económica a través del trabajo asalariado de las mujeres temporeras, asalariadas o microempresarias, es un ámbito revulsivo para el modelo tradicional en el medio rural generándose diversas disfuncionalidades y nuevos ordenamientos en las relaciones familiares y de pareja. El avance laboral femenino, no obstante, reproduce al interior del sistema familiar el modelo cultural tradicional destinándose los recursos obtenidos principalmente a satisfacer necesidades domésticas y familiares. Sin embargo, se aprecia una mayor autovaloración en el sentirse útil y necesaria (coherente con la feminidad tradicional de valorar el trabajo cuando es para otros) y sentirse dueña de sí misma (coherente con feminidad de la modernidad radical). Esto último se refuerza con la socialización vicaria a través de la exposición de modelos femeninos autónomos en los medios de comunicación. Las mujeres rurales son influidas por el modelo de feminidad de mayor autonomía especialmente en aquellas que viven en espacios familiares asimilados a los diversos modelos de familia que se legitiman en la modernidad.

En otra dimensión de estos espacios, se aprecia un cambio en la significación del cuerpo y la sexualidad de las mujeres, hay una apertura a romper con creencias asociadas a la pasividad sexual de la mujer, adueñarse de su propio cuerpo y resignificar hitos fisiológicos como la menopausia. De esta forma podríamos señalar que hay un cambio a nivel subjetivo de las mujeres que se instalan culturalmente desde la modernidad radical, que no va acompañado de un cambio a nivel intersubjetivo en el sistema sexo-género debido a que la masculinidad no ha sido afectada mayormente, salvo en la incursión de los cuidados donde se permite la expresión emocional hasta ahora reservada para la feminidad. Para los hombres la socialización vicaria continua siendo hacia una representación tradicional de la masculinidad, esto produce una tensión respecto a los cambios experimentados por las mujeres, que provocan en los hombres desconcierto que puede provocar una disposición al cambio, una apertura hacia la igualdad o una incomprensión, resistencia y coerción hacia la mujer, dependiendo del espacio cultural que comparta.

Además, identificamos tres situaciones emergentes, la primera el aumento de la homosexualidad y bisexualidad en los hombres, (no así en las mujeres, de acuerdo a lo indagado) y la violencia de género, el desconocimiento de la vivencia de violencia a través de la biografía de las mujeres y la incipiente reivindicación de derechos de los hombres en igualdad con las mujeres, por ejemplo respecto a la violencia de género algunos hombres refieren ser víctimas de violencia por parte de sus parejas en violencia sexual y económica. Esto lleva a reflexionar sobre dos aspectos; 1 . La resistencia de la masculinidad hacia la igualdad entre hombres y mujeres y 2 . El inicio de la reflexividad masculina sobre su sometimiento cultural en el sistema sexo-género, aunque persiste la resistencia a relacionarla con el orden patriarcal y androcéntrico, desde una perspectiva machista continúan centrándose en la disputa sustentada en el orden natural de la subordinación reaccionando a la sublevación de las mujeres.

Los cambios a nivel del sistema sexo-género suponen para las mujeres resignificaciones subjetivas que no son acompañadas por una redefinición social de la feminidad lo cual reproduce el ejercicio de una ciudadanía pasiva. Respecto a los hombres se percibe una tensión en la subjetividad que, a pesar de los incipientes cambios, se asocia a la matriz tradicional y permite la preeminencia social propia de la masculinidad en un ejercicio de ciudadanía activa. De tal forma, encontramos en estos ámbitos un amplio campo en que actualmente se asiste a nuevas realidades y acomodaciones; en que las generaciones de jóvenes y adultos-jóvenes se constituyen en las cohortes que experimentan de manera significativa los nuevos ordenamientos de género que expresan las transiciones a nuevas identidades de género, lo cual nos atrevemos a enunciar, se constituirán en las más importantes transformaciones en el medio rural para las próximas generaciones.

\section{Los jóvenes rurales como facilitadores de los cambios}

Los proyectos de vida se constituyen en un espacio simbólico con grados de libertad para los jóvenes que se ven interpelados en el ejercicio de la opcionalidad en las decisiones que adquieren como nunca mayor nivel de expresión subjetiva y menor determinación de los adultos de la familia. Adquiere relevancia el rol de los modelos que circulan ya no sólo en los medios de comunicación sino los validados por la comunicación horizontal entre los mismos jóvenes. El impacto de los estilos de vida que son promovidos de manera directa e indirecta por estas fuentes socializadoras secundarias producen una menor distancia psicológica de estos jóvenes con sus pares urbanos o suburbanos.

Por otra parte, al tener, generalmente, los jóvenes mayor nivel educacional que las anteriores generaciones y al presentar capacidades manifiestas en la alfabetización digital se produce un rol legitimador de los jóvenes y pasan a cumplir funciones facilitadoras en el relacionamiento con los agentes externos de la modernidad con que se interactúa, por ejemplo, en la comercialización de los productos de la agricultura familiar y en las tramitaciones de todo tipo que implican interacción con las burocracias de la modernidad. Este papel lo hemos denominado de traductores que posibilitan un rol protagónico, que no se tenía con anterioridad, desde mínimos a complejos procesos de intercambio. Los jóvenes tienen un desempeño de alta facilitación de estos procesos. En la representación social de los adultos de su grupo familiar se destaca la capacidad y competencias de los jóvenes para ser efectivos ante los agentes externos para moverse en un territorio al que entran y salen sin mayores complicaciones. Esta constatación nos refiere las competencias para vivir y funcionar en los dos mundos; en las dos realidades hay claridad en las destrezas que son cada vez más considerables en cantidad y calidad para hacer frente a las complejidades de la vida moderna, la cual no distingue entre rural y urbano en términos 
operativos, si no que exige condiciones de funcionamiento para una operación equivalente en ambas realidades donde lo rural se entiende en procesos de transición y convulsión permanentes.

\section{A MODO DE COROLARIO}

Las nuevas realidades del mundo rural actual se han visto dramáticamente determinadas por los profundos procesos de transformaciones en los estilos y formas de vida que han constituido en clave de cambio cultural la conformación de nuevos procesos identitarios y de representación social de sí mismo. Así, los significados autoatribuidos a la ruralidad y, por consiguiente, a las nuevas ruralidades deben comprenderse en la multiplicidad de nuevas relaciones con agentes externos e internos, globales y locales, y a través de dimensiones de significado emergentes que se configuran, de forma convergente y también divergente, con los contenidos de las nuevas y anteriores R. S. de la ruralidad. Significados que en ocasiones se ensamblan, intersectan o contraponen en los repertorios cognoscitivos de las identidades individuales y colectivas, conformando una mixtura de contenidos culturales que construyen la intersubjetividad de las comunidades rurales actuales. Las comunas de estas dos regiones de Chile central son espacios de una intensa acción de cambio que permiten comprender en toda su intensidad las transformaciones no sólo de la ruralidad sino de la realidad nacional.

\section{BIBLIOGRAFÍA}

ARENDT, H. (1987) “L'intérêtpour la politique”, Les Cahiers de Philosophie $N^{\circ} 4$, París, Francia.

BAUMAN, Z. (2015) Entrevista en Artes y Letras, Diario El Mercurio, 27 de setiembre, p. 14.

BAUMAN, Z. (2008) "Tiempos líquidos”, Buenos Aires: Tusquets.

BECK, U., GIDDENS, A. \& LASH, S. (1997) “Modernización reflexiva: Política, tradición y estética en el orden social moderno", Madrid: Alianza Universidad.

BERDEGUÉ, J., JARA, E., MODREGO, F., SANCLEMENTE, X. \& SCHEJTMAN, A. (2010) "Comunas Rurales de Chile", documento de trabajo $\mathrm{N}^{\circ} 60$, Programa Dinámicas Territoriales Rurales, Santiago: Rimisp.

CASTELLS, M. (1998) "La Era de la Información: Economía Sociedad y Cultura”, Madrid: Alianza Editorial.

GARCÍA CANCLINI, N. (1999) “La Globalización Imaginada”, Buenos Aires: Editorial Paidós.

GARCÍA CANCLINI, N. (1992) “Culturas Híbridas: estrategias para entrar y salir de la modernidad”, Buenos Aires: Editorial Sudamericana.

GIDDENS, A. (1999) "Consecuencias de la Modernidad", Madrid: Alianza Editorial.

GIDDENS, A. (1996) "Modernidad e Identidad del yo: El yo y la sociedad en la época contemporánea”, traducido por J. L. Gil Aristu, Barcelona: Península.

GONZÁLEZ, S. 2010 “Identidad, ciudadanía y nueva ruralidad: EI impacto de las modernizaciones en localidades rurales de la región Metropolitana de Chile". En: La Ruralidad Chilena Actual: Aproximaciones desde la Antropología, editado por R. Hernández y L. Pezo, Santiago: CoLibris, pp. 111-134.
GONZÁLEZ, S. (2008) “Individuación y Juventud: Proyectos de Vida y Derechos Subjetivos", Revista Observatorio de Juventud INJUV, 20, Santiago, pp. 27-35.

GONZÁLEZ, S. (2006) "Nuevos Imaginarios de la Ruralidad en Chile”, Revista Chilena de Antropología, 18, Santiago, pp. 9-30.

JODELET, D. (1984) “La Representación Social: Fenómenos, Conceptos y Teoría". En: Moscovici, S. en Psicología Social: Pensamiento y vida social, Psicología social y problemas sociales, Barcelona: Editorial Paidós, pp. 469-495.

LARRAÍN, J. (1994) “La Identidad Latinoamericana: Teoría e Historia”, Estudios Públicos Nº 55, Centro de Estudios Públicos, Santiago.

MoscoVICI, S. (1993) "Psicología Social, II: Pensamiento y vida social. Psicología Social y problemas sociales", Bs. Aires: Editorial Paidós.

MOSCOVICI, S. (1988) "Notes towards a description of social representations", En: European Journal of Social Psychology, 18, pp. 211-250.

PÁVEZ, A. (2013) “La Enfermería, realidad de ciudadanía y de género en Chile", Ciencia y Enfermería, 19 (3), pp. 95-102.

PNUD (2008) "Desarrollo Humano en Chile Rural: Seis millones por nuevos caminos", Santiago: PNUD.

RICOEUR, P. (1995) “El sí mismo como un otro", México: Fondo de Cultura Económica.

\section{NOTAS}

1 Este artículo forma parte de los resultados obtenidos en la investigación realizada en el Proyecto CONICYT-PAI N 791220019 y en Proyecto sobre Ruralidad en la Intendencia Región Metropolitana 2005-2009.

2 Con la dictación de la Ley 16.625 de Sindicalización campesina y de la Ley 16.640 de la Reforma Agraria se instituyó el proceso de organización social más grande conocido en la historia de Chile, al crearse la sindicalización campesina hasta entonces ilegal, se pasó de 1.200 trabajadores afiliados en 1964 a más de 300 mil campesinos organizados en 1970. Junto a ello, se contaba en esos años con casi mil asentamientos campesinos, y la producción agropecuaria del país, en plena reforma agraria y sindicalización campesina, aumentó de 1,6\% en 1964 a cerca de 5\% en el período entre 1970 y 1971.

3 La noción de representación social se refiere a las imágenes que condensan un conjunto de significados, entendiéndolas como sistemas de referencia que permiten interpretar el comportamiento social determinado por categorías que sirven para clasificar las circunstancias, los hechos y las personas. Este concepto aporta información acerca de la manera de cómo se aprehenden los acontecimientos de la vida cotidiana, las características del medio ambiente físico y social, las informaciones que por él circulan y a las personas de nuestro entorno próximo o lejano. Este conocimiento se constituye a través de la experiencia, pero también, mediante las informaciones, conocimientos y modelos de pensamiento que recibimos y transmitimos a través de la tradición, educación y la comunicación social. De este modo, este conocimiento es, un conocimiento socialmente elaborado y compartido. 